\title{
Die Erfindung des Nordpols
}

\section{Erhard Taverna}

erhard.taverna[at]saez.ch
Jahrzehntelang propagierte er seinen Highway zum eisfreien Polarmeer, bequem im Winter zwischen Spitzbergen und Nowaja Semlja zu erreichen. Am Vorhaben, den dazwischenliegenden Eiswall mit Dampfkraft zu durchbrechen, sind viele Expeditionen gescheitert. Ein posthum geborgenes Tagebuch berichtete 1881 vom trostlosen Ende der Mannschaft: «Erbittert verfluchten wir Petermann und all seine Werke, die uns in die Irre geführt hatten.»

Der 1972 geborene Historiker Philipp Felsch war bis 2011 wissenschaftlicher Mitarbeiter an der Professur für Wissenschaftsforschung der ETH Zürich und Stipendiat des Schweizerischen Nationalfonds. Seine Erzählung «Wie August Petermann den Nordpol erfand» [1] kann man als Entwicklung der Kartographie, Wettlauf zum Nordpol, europäische Kulturgeschichte des 19. Jahrhunderts oder als Beitrag zum Thema Theorie und Praxis lesen. Petermann war ein talentierter deutscher Zeichner, dessen thematische Karten zur Geburtsstunde der modernen Gesundheitsstatistik gehören. In London verhalfen sie dem Arzt John Snow zu seiner berühmten Entdeckung der Ansteckungswege von Cholera. Als Teilnehmer an den regelmässigen Treffen der Royal Geographical Society war Petermann Zeuge der vergeblichen Suchaktionen nach John Franklin, der 1845 mit dem Auftrag, die Nordwestpassage zu entdecken, in See gestochen und seither verschollen war. Die Hypothesen eines eisfreien Polarmeeres weckten neue Hoffnungen. Der Kartograph kannte die ganze bekannte Reiseliteratur, er zitierte Kronzeugen, rechnete Isothermen und schuf aus statistischen Daten ein arktisches Arkadien, das unter wissenschaftlichen Vorzeichen lückenlos die Mythen über das geheimnisvolle Gebiet am nördlichen Ende der Welt fortschrieb. Während er auf dem Höhepunkt seiner Kampagne 1852 von der Königin Viktoria persönlich ausgezeichnet wurde, kritisierten ihn die Lords der Admiralität. Von einem deutschen Stubengelehrten, einem «armchair explorer», mochten sie sich nicht vorschreiben lassen, was zu unternehmen sei. «Das Meer gehört den Briten, wir aber besitzen im Luftreich des Traums die Herrschaft unbestritten», spottete Heinrich Heine.

Petermann leitete später in Gotha ein international renommiertes Institut, brachte ein vielbeachtetes Fachmagazin heraus und gehörte mit zwei Goldmedaillen zur Expertenprominenz. Die Hansestädte, Bismarck, die österreichisch-ungarische Marine und amerikanische Millionäre waren an ihm interessiert, unzählige Freiwillige spendeten Geld und bemühten sich um Mithilfe und Teilnahme an bevorstehenden Expeditionen, die mehrmals Kriege verhinderten. Bis zu seinem Suizid 1879 hielt der Gelehrte an seiner Hypothese fest, der erst der Polarforscher Robert Peary am 6. April 1909 definitiv ein Ende setzte.

Viele teilten Petermanns Wunschdenken, das jeden Widerspruch zum System als Kränkung überging. Schon Hegel hatte gefordert, «den Gesamtstoff der Erdkunde in das Gebiet des Gedankens zu versetzen». Im Land der Kleinstaaterei, der Dichter und Denker fiel das auf offene Ohren, man war darin geübt, die Welt im Kopf zu erobern. Petermann vereinigte die Visionen eines weltfremden Spinners mit mathematischer Begabung und handwerklichem Können. Eine zu allen Zeiten unwiderstehliche Kombination. Kein Jahrestag erinnert an die Tragödie des begabten, längst vergessenen Bücherwurms, der nie im Leben einen Eisberg sah, aber alles über sie zu wissen glaubte. Lehnstuhlforscher geniessen kein hohes Prestige. Dabei leben die meisten Menschen vom Sekundärwissen, das sie gläubig übernehmen.

Zumindest die medizinische Propädeutik ist ein Paradebeispiel für gepauktes Papierwissen, dem meist die praktische Grundierung fehlt. Die Medizingeschichte ist voll von unkritisch übernommenen Autoritäten, wie alle Anatomietafeln, nichts anderes als Landkarten, vor Vesalius bezeugen. Die weis-sen Flecken der Kartographie gehen nie aus. Zwar haben die Erdpole ihre Magie eingebüsst, dafür sind wir datengläubiger denn je. Die neuen Mythen liegen hinter den digitalen Datenbergen, wo virtuelle Welten Hoffnungen wecken, die Petermanns Karten in nichts nachstehen. Wo Informationen wie nie zuvor als Ware unseren Alltag bestimmen, sind wir ebenso beeinflussbar wie die Zeitgenossen imperialer Wettläufe des alten Europa. Am Ende sorgt der Klimawandel dafür, dass der weltfremde Spinner aus Gotha gut hundert Jahre später doch noch recht bekommt. Wenn die Polkappen schmelzen, locken neue Schiffsrouten und Rohstoffreserven. Der Kampf um Nutzungsrechte und Wirtschaftszonen wird das Wettrüsten weiter anheizen. Für Petermann \& Co. brechen vielversprechende Zeiten an.

1 Felsch P. Wie August Petermann den Nordpol erfand. München: Btb Taschenbuch; 2013. Auf Französisch: Comment August Petermann inventa le pôle nord. Paris: Editions de la maison des sciences de l'homme; 2013. 